\title{
Severe intellectual disability-poor language-strabismus-grimacing face-long fingers syndrome
}

INSERM

\section{Source}

INSERM. (1999). Orphanet: an online rare disease and orphan drug data base. Severe intellectual disability-poor language-strabismus-grimacing face-long fingers syndrome. ORPHA:363686

Severe intellectual disability-poor language-strabismus-grimacing face-long fingers syndrome is a rare, genetic, syndromic intellectual disability disorder characterized by global development delay with very limited or absent speech and language, severe intellectual disability, long slender fingers, ocular abnormalities (typically strabismus or hypermetropia), and facial dysmorphism that includes a grimacing facial expression, a tubular-shaped nose with a prominent, broad base and tip, and other variable features, such as broad forehead, hypertelorism, deep-set eyes, narrow palpebral fissures, short philtrum and/or broad mouth. 